\title{
Role of Chlamydia trachomatis in non-acute prostatitis
}

\author{
P.-A. MÅRDH,* K. T. RIPA,* S. COLlEEN, $\dagger$ J. D. TREHARNE, \\ AND S. DAROUGAR \\ From the *Institute of Medical Microbiology, University of Lund; †Department of Urology, University \\ Hospital, Lund; and $\ddagger$ Virus Laboratory and WHO Collaborating Centre for Reference and Research on \\ Trachoma and other Chlamydial Infections, Department of Clinical Ophthalmology, Institute of \\ Ophthalmology, University of London
}

SUMMARY The possible role of Chlamydia trachomatis in non-acute prostatitis was investigated by cultural and serological techniques in a study of 53 adult males. $C$. trachomatis was isolated from the urethra of only one of the 53 patients and from none of the 28 specimens of prostatic fluid from the same patients. By means of a modified microimmunofluorescent test, serum chlamydial IgG antibodies at a titre of $1 / 64$ or greater, or IgM antibodies at a titre of $1 / 8$ or greater, or both were detected in six of the patients, suggesting a recent or current chlamydial infection, while IgG or IgA antibodies at a titre of $1 / 8$ or greater were detected in the specimens of prostatic fluid from two of the 28 men studied. In the seven patients with evidence of chlamydial infection, as well as in a further 13 of the 53 patients studied, the presenting symptoms suggested non-gonococcal urethritis (NGU) rather than prostatitis. Thus in this study C. trachomatis would appear to play a minor aetiological role, if any, in non-acute prostatitis.

\section{Introduction}

In contrast to the rare condition of 'acute bacterial prostatitis', which is associated with recurrent urinary tract infections and is generally caused by bacteria belonging to the family Enterobacteriaceae (Meares and Stamey, 1968), the aetiology of the comparatively common condition of non-acute prostatitis is, except in a few cases, still not known (Colleen and Mårdh, 1975a).

Chlamydia trachomatis has recently been established as a frequent cause of sexually transmitted diseases (Oriel et al., 1976; Alani et al., 1977; Bowie et al., 1977; Mardh et al., 1977; Rees et al., 1977; Ridgway and Oriel, 1977; Woolfitt and Watt, 1977; Ripa et al., 1978a, 1978b). The organism has been found in $30-70 \%$ of all cases of non-gonococcal urethritis (NGU), a condition which is probably more common than gonococcal urethritis (Wiesner, 1977). C. trachomatis has also been associated with acute epididymitis (Harnisch et al., 1977; Berger et al., 1978).

Address for reprints: Dr P.-A. Mårdh, Institute of Medical Microbiology, Sölvegatan 23, S-223 62 Lund, Sweden

Received for publication 24 April 1978
The present study was undertaken to investigate the presence of genital chlamydial infection in patients with symptoms of non-acute prostatitis using cultural and serological methods.

\section{Material and methods}

STUDY POPULATION

The study comprised 53 men, with a mean age of 32 years (standard deviation $8 \cdot 7$ ), and a range of 22-58 years. Of these patients, 50 had presented because of symptoms of non-acute prostatitis, that is, dull pain over the bladder which often spread down to the groins, to the testicles, the lower back, the perineum, and along the inner aspects of the thighs. In addition, symptoms of slight urethral obstruction and discharge were commonly found. Generally these patients had had symptoms intermittently for many years (mean 3.5 years; standard deviation $3 \cdot 6$; range $0.5-18$ years). Three of the 53 patients were diagnosed as having non-acute prostatitis when investigated for infertility. Of these three, none had had symptoms of urogenital tract infection. Twenty of the patients had first presented with episodes of urethritis; in eight of these, gonococci were isolated at that time. In a further patient 
the symptoms of prostatitis had started following an episode of epididymitis; neither gonococci nor established urinary tract pathogens were isolated at that time. Furthermore, one patient had had a slight urethral discharge and polyarthritis which had persisted for two years. None of the 53 patients studied showed signs of urinary tract infection, that is, bacteriuria or pyuria or both.

In addition to the history and clinical findings the diagnosis of non-acute prostatitis was based on the presence of more than 15 leucocytes per $\times 45$ microscopic field in expressed prostatic fluid (Colleen and Mårdh, 1975a).

Of the 53 patients, 28 had completed their last course of antibiotic treatment (tetracyclines were generally used) more than six months before taking part in the study, and 20 between one and six months. Of the remaining five patients, four were taking tetracyclines when studied and one had finished treatment one week before examination.

SAMPLING AND ISOLATION TECHNIQUES

Urethral specimens for the culture of $C$. trachomatis and Neisseria gonorrhoeae were obtained from all 53 patients. The samples were collected and transported as previously described (Ripa et al., 1978a). Sufficient expressed prostatic fluid was obtained to carry out cultures for $C$. trachomatis and $N$. gonorrhoeae in 28 patients. The isolation methods used for $N$. gonorrhoeae (Mårdh et al., 1978) and C. trachomatis (Ripa and Mårdh, 1977) were those reported elsewhere.

Serum specimens were collected from 50 of the patients, which included 25 of the 28 patients from whom prostatic fluid had also been obtained. Both serum and prostatic fluid specimens were used for the serological tests.

\section{SEROLOGICAL TESTS}

The presence of antibodies to $C$. trachomatis in sera and prostatic fluid was determined by a modified microimmunofluorescence (micro-IF) test (Treharne et al., 1977a). Four pools of chlamydial antigens were used: pool 1 contained TRIC agent, serotypes A, B, and C; pool 2 TRIC agent, serotypes D, E, F, G, H, I, and K; pool 3 LGV serotypes 1,2 , and 3 ; while pool 4 contained antigens prepared from selected strains of Chlamydia psittaci (Treharne et al., 1977b).

The titres of IgG and IgM antibodies to these pools of antigens were determined in the serum specimens, and those of IgG and IgA antibodies to the same antigens in the specimens of prostatic fluid. The lowest serum dilution used for testing IgG antibodies in serum was $1 / 16$, while that for IgM in serum and IgG and IgA in prostatic fluid was $1 / 8$. The presence of IgM antibodies at a titre of $1 / 8$ or greater or IgG antibodies at a titre of $1 / 64$ or greater, or both, in serum specimens was considered as evidence of active chlamydial infection.

\section{Results}

\section{ISOLATION STUDIES}

C. trachomatis was isolated from the urethra of one of the 53 patients. In three of the patients the cell cultures were destroyed by a nonspecific cytopathogenic effect, and the presence of chlamydiae could therefore not be established. The chlamydial cultures of the 28 prostatic fluid specimens were spoiled in one instance, and $C$. trachomatis could not be isolated in any of the remaining 27 specimens. $N$. gonorrhoeae was not isolated from any of the 53 patients.

\section{SEROLOGICAL TESTS}

The results of the micro-IF tests for IgG antibodies to $C$. trachomatis in the 50 serum specimens are shown in the Table. Four of the specimens contained these antibodies at a titre of $1 / 64$ or greater, three of them reacting with the pool 2 antigens and the fourth with the antigens of both pool 2 and 3. IgM antibodies to $C$. trachomatis were found in four serum specimens, the titres being $1 / 8$ in two specimens and $1 / 16$ and $1 / 32$ in each of the other two. Two of the specimens with chlamydial antibodies reacted with the antigens of both pool 2 and 3 , while the other two reacted only with the pool 2 antigens. None of the 50 specimens contained antibodies to the $C$. psittaci antigens included in the test.

Of the 28 prostatic fluid specimens one gave an IgG antibody titre of $1 / 32$ and one an IgG antibody titre of $1 / 16$ and an IgA antibody titre of $1 / 8$. The IgG antibodies in the two specimens reacted with the pool 2 and 3 antigens.

The patient with IgA antibodies to $C$. trachomatis in prostatic fluid at a titre of $1 / 32$ had a serum IgG titre of $1 / 32$ and an IgM titre of $1 / 8$. A specimen of

Table Numbers of patients with non-acute prostatitis with reciprocal titres of type-specific chlamydial antibodies detected by an immunofluorescence test

\begin{tabular}{lllllllllll}
\hline & \multicolumn{1}{l}{ Antibody titres } & & $\begin{array}{l}\text { Total no. } \\
\text { Serum antibodies }\end{array}$ \\
\cline { 2 - 10 } & $<8$ & 8 & 16 & 32 & 64 & 128 & 256 & patients \\
\hline IgG & 43 & ND & 0 & $3 *$ & $1 \dagger$ & $1+$ & 25 & 50 \\
IgM & 46 & 2 & 1 & 1 & 0 & 0 & 0 & 50
\end{tabular}

ND Not done

* IgM antibody titre $1 / 8$ in two patients

† Only patient culture-positive for $C$. trachomatis

$\ddagger$ IgM antibody titre $1 / 16$

IgM antibody titre $1 / 32$ in one patient 
serum was not obtained from the other patient in whom antibodies to $C$. trachomatis were found in the prostatic secretion. Prostatic fluid from another patient with serum IgG antibodies at a titre of $1 / 128$ and IgM antibodies at a titre of $1 / 16$ did not contain any detectable chlamydial antibodies.

CORRELATION OF CLINICAL FINDINGS WITH CULTURAL AND SEROLOGICAL TESTS The clinical signs and symptoms in six of the seven patients with antibodies in serum or prostatic fluid or both, indicating active chlamydial infection, did not differ from those in the other 46 patients. The remaining seropositive patient had polyarthritis resembling Reiter's syndrome. All seven patients with antibodies first presented with NGU, as did a further 13 of the 53 patients.

The patient who had previously had an acute episode of epididymitis had chlamydial antibodies in both serum and prostatic fluid specimens. In the entire series of patients, eight of whom had previously had gonorrhoea, four had chlamydial antibodies.

The only patient with positive results to cultural and serological tests had finished three-weeks' doxycycline treatment one week before sampling. Of the remaining six patients with chlamydial antibodies three had been given tetracycline one to four months previously, and another two patients had had tetracycline two years previously. The patient with polyarthritis had never received antibiotic treatment.

Three of the seven patients with serological evidence of chlamydial infection had, as discovered retrospectively, been given doxycycline after sampling (100 mg daily for three weeks) and had become symptomless for some months. However, recurrent episodes or reinfections occurred later. This contrasted with the remaining three seropositive patients who were not given antibiotics and in whom the symptoms persisted.

\section{Discussion}

C. trachomatis is an established cause of acute urethritis in men. The organism may invade the accessory genital glands as demonstrated in patients with acute epididymitis in whom specimens collected from the epididymis by aspiration were culturepositive for C. trachomatis (Berger et al., 1978). This might also suggest an aetiological role of C. trachomatis in prostatitis.

The frequency of isolation of $C$. trachomatis in the present series of patients with non-acute prostatitis (one out of 53 patients) is very low compared with that in a series of consecutive male patients $(24.6 \%$ or 222 out of 902$)$ from the same hospital catchment region attending a venereal diseases clinic because of symptoms of acute urethritis (Mardh et al., unpublished data).

The patients with non-acute prostatitis had generally had their disease for several years. These patients may have harboured Chlamydia which was possible to detect by cultural methods at an early stage of the disease. The occurrence of chlamydial antibodies in the urethral secretion and expressed prostatic fluid, or a cellular immune response, or both might have interfered with the isolation of Chlamydia in the non-acute condition studied. Thus there may be an analogous situation with that of ocular hyperendemic trachoma, where it is possible to isolate $C$. trachomatis from $70 \%$ of acute cases but from only $5 \%$ of chronic (stage III-IV), complicated trachoma cases (Darougar et al., 1977).

Contamination of the prostatic fluid with the contents of the urethra is a problem in aetiological studies of inflammatory conditions of the prostate, such as non-acute prostatitis. The use of prostatic biopsy specimens for culture to isolate an infectious agent in non-acute prostatitis is hampered by the risks involved in taking such specimens (Esposti et $a l .$, 1975). Thus, serodiagnostic methods may prove more valuable in aetiological studies of non-acute prostatitis.

In an earlier study (Mårdh et al., 1972) we used a complement fixation test (CF) to detect antibodies to Chlamydia in patients with non-acute prostatitis. Of the 79 patients studied $33 \%$ had CF antibodies at a titre of $1 / 5$ or greater compared with $3 \%$ of 72 blood donors matched for age. We thought it worthwhile to investigate again patients with nonacute prostatitis for chlamydial antibodies, this time using the more recently developed, highly specific micro-IF technique. With this serodiagnostic technique we found that $12 \%$ of the 50 patients in the present series had evidence of a recent or current infection with $C$. trachomatis (IgM antibodies at a titre of $1 / 8$ or greater, or IgG antibodies at a titre of $1 / 64$ or greater, or both). However, if a titre of $1 / 16$ for IgG chlamydial antibodies is included one further patient of the 53 studied would be considered seropositive. Chlamydial antibodies were found in the prostatic secretions in only two of the 28 patients.

By means of the micro-IF technique, $51 \%$ of men with NGU and positive cultures for C. trachomatis had IgG antibodies at a titre of $1 / 8$ or greater. In men with NGU but negative cultures for Chlamydia the corresponding figure was $10 \%$ (Treharne et al., 1977b).

In another study, we found no evidence of bacteria as the cause of non-acute prostatitis 
except in a few cases. Using an immunofluorescent technique we found gonococci in prostatic fluid specimens in about $10 \%$ of the 79 patients studied, but it was not possible to isolate the bacteria from these patients. Mycoplasma hominis was cultured from $10 \%$ of the patients but from none of the 20 controls studied, while Ureaplasma urealyticum was no more common in the patients than in the controls. Furthermore there was no evidence of infection with Trichomonas vaginalis, Candida species, or viruses, except in isolated cases (Mårdh and Colleen, 1975). In a further series of 21 patients with non-acute prostatitis we could not culture Staphylococcus saprophyticus from any of the patients studied using a selective culture technique (Mårdh et al., unpublished data). Thus the results of these microbiological studies, including the present one, suggest that the aetiological agent of non-acute prostatitis is still unknown in most cases.

Negative microbiological findings might suggest a non-infectious cause in many cases of non-acute prostatitis. Patients with this condition often have a poorly developed sex identification and some use their symptoms as an excuse to avoid sexual intercourse, while others repeatedly feel themselves forced to find new female sexual partners to prove their manliness (Nilsson et al., 1975). These latter patients are likely, therefore, to acquire sexually transmitted diseases.

Of the seven patients in the present study with evidence of active chlamydial infection, it is noteworthy that four had previously had gonorrhoea. Of the total of 53 patients, eight had definitely had gonorrhoea. The presence of $C$. trachomatis has been shown to be closely associated with concomitant infection with $N$. gonorrhoeae (Richmond et al., 1972). Of the three remaining patients with seropositive results, one had had acute epididymitis and one had a Reiter-like syndrome. Both these conditions (Harnisch et al., 1977; Keat et al., 1978; Kousa et al., 1978) have been associated with chlamydial infection.

The effect of antibiotic treatment in patients with non-acute prostatitis is difficult to assess, because these patients are often psychologically disturbed (Nilsson et al., 1975). Such disturbances have an effect on symptoms, regardless of whether or not antibiotic treatment is given. Since recurrences are a characteristic of non-acute prostatitis, the length of follow up is also important in assessing the value of any treatment in this condition (Colleen and Mårdh, 1975b).

Tetracycline treatment for one to three weeks in men with acute urethritis from whom $C$. trachomatis had been isolated generally results in negative urethral cultures and a disappearance of the signs of infection (Oriel et al., 1975; Alani et al., 1977; Ripa et al., 1978a). Although no definite conclusions can be drawn from the seven patients with chlamydial antibodies, it is noteworthy that in those three who were given doxycycline the symptoms and signs had disappeared on re-examination one month after they had completed treatment but that they persisted in the four who received no treatment. Thus, although evidence of $C$. trachomatis infection was not found in many of the patients studied, this does not preclude the fact that this organism may play a role in some cases of non-acute prostatitis.

This study was supported by grant No. $16 \mathrm{X}-0459$ from the Swedish Medical Research Council and by grants from the Department of Health and Social Security, London.

\section{References}

Alani, M. D., Darougar, S., MacD. Burns, D. C., Thin, R. N., and Dunn, H. (1977). Isolation of Chlamydia trachomatis from the male urethra. British Journal of Venereal Diseases, 53, 88-92.

Berger, R. E., Alexander, E. R., Monda, G. D., Ansell, J., McCormick, G., and Holmes, K. K. (1978). Chlamydia trachomatis as a cause of acute 'idiopathic' epididymitis. New England Journal of Medicine, 298, 301-304.

Bowie, W. R., Wang, S.-P., Alexander, E. R., Floyd, J., Forsyth, P. S., Pollock, H. M., Lin, J.-S., Buchanan, T. M., and Holmes, K. K. (1977). Etiology of non-gonococcal urethritis. Evidence for Chlamydia trachomatis and Ureaplasma urealyticum. Journal of Clinical Investigation, 59, 735-742.

Colleen, S., and Mårdh, P.-A. (1975a). Studies on non-acute prostatitis. Clinical and laboratory findings in patients with symptoms of non-acute prostatitis. In Genital Infections and their Complications, pp. 121-131. Edited by D. Danielsson, L. Juhlin, and P.-A. Mårdh. Almqvist and Wiksell International: Stockholm.

Colleen, S., and Mårdh, P.-A. (1975b). Effect of metacycline treatment of non-acute prostatitis. Scandinavian Journal of Urology and Nephrology, 9, 198-204.

Darougar, S., Woodland, R. M., Forsey, T., Cubitt, S., Allami, J., and Jones, B. R. (1977). Isolation of Chlamydia from ocular infections. In Nongonococcal Urethritis and Related Infections, pp. 295-298. Edited by D. Hobson and K. K. Holmes. American Society for Microbiology: Washington, D.C.

Esposti, P. L., Elman, A., and Norten, H. (1975). Complications of transrectal aspiration of the prostate. Scandinavian Journal of Urology and Nephrology, 9, 208-213.

Harnisch, J. P., Berger, R. E., Alexander, E. R., Monda, G., and Holmes, K. K. (1977). Aetiology of acute epididymitis. Lancet, 1, 819-821.

Keat. A. C., Maini, R. N., Kwazi, G. C., Pegrum, G. D., Ridgway, G. L., and Scott, J. T. (1978). Role of Chlamydia trachomatis and HLA-B27 in sexually acquired reactive arthritis. British Medical Journal, 1, 605-607.

Kousa, M., Saikku, P., Richmond, S., and Lassus, A. (1978). Chlamydia infection in Reiter's disease. Sexually Transmitted Diseases, in press.

Mårdh, P.-A., Colleen, S., and Holmquist, B. (1972). Chlamydia in chronic prostatitis. British Medical Journal, 4, 361.

Mårdh, P.-A., and Colleen, S. (1975). Search for uro-genital tract infections in patients with symptoms of prostatitis. Scandinavian Journal of Urology and Nephrology, 9, 8-16.

Mårdh, P.-A., Ripa, T., Svensson, L., and Weström, L. (1977). Chlamydia trachomatis infection in patients with acute salpingitis. New England Journal of Medicine, 296, 1377-1379.

Mårdh, P.-A., Mårtensson, D., Soltesz, V. (1978). A new effective culture medium for Neisseria gonorrhoeae. Sexually Transmitted Diseases, 5, 10-13.

Meares, E. M., and Stamey, T. A. (1968). Bacteriologic localization patterns in bacterial prostatitis and urethritis. Investigative Urology, 5, 492-518. 
Nilsson, I.-K., Colleen, S., and Mårdh, P.-A. (1975). Relationship between psychological and laboratory findings in patients with symptoms of non-acute prostatitis. In Genital Infections and their Complications, pp. 133-144. Edited by D. Danielsson, L. Juhlin, and P. A. Mårdh. Almqvist and Wiksell International; Stockholm.

Oriel, J. D., Reeve, P., and Nicol, C. S. (1975). Minocycline in the treatment of non-gonococcal urethritis: Its effect on Chlamydia trachomatis. Journal of the American Disease Association, 2, 17-22.

Oriel, J. D., Reeve, P., Wright, J. T., and Owen, J. (1976). Chlamydial infection of the male urethra. British Journal of Venereal Diseases, 52, 46-51.

Rees, E., Tait, I. A., Hobson, D., and Johnson, F. W. A. (1977). Chlamydia in relation to cervical infection and pelvic inflammatory disease. In Nongonococcal Urethritis and Related Infections, pp. 67-76. Edited by D. Hobson and K. K. Holmes. American Society for Microbiology: Washington, D.C.

Richmond, S. J., Hilton, A. L., and Clarke, S. K. R. (1972). Role of Chlamydia Subgroup $A$ in non-gonococcal and post-gonococcal urethritis. British Journal of Venereal Disease, 48, 437-444.

Ridgway, G. L., and Oriel, J. D. (1977). Interrelationship of Chlamydia trachomatis and other pathogens in the female genital tract. Journal of Clinical Pathology, 30, 933-936.

Ripa, K. T., and Mårdh, P.-A. (1977). Cultivation of Chlamydia trachomatis in cycloheximide-treated McCoy cells. Journal of Clinical Microbiology, 6, 328-331.
Ripa, K. T., Mårdh, P.-A., and Thelin, I. (1978a). Chlamydia trachomatis in men attending a venereal disease clinic. Acta dermatovenereologica, 57, 175-179.

Ripa, K. T.. Svensson, L., Mårdh, P.-A., and Weström, L. (1978b). Chlamydia trachomatis cervicitis in gynecological out-patients. Obstetrics snd Gynecology, in press.

Stamey, T. A. (1972). Urinary tract infections in males. In Urinary Infections, pp. 161-211. Edited by T.A. Stamey. Williams and Wilkins: Baltimore.

Treharne, J. D., Darougar, S., and Jones, B. R. (1977a). Modification of the microimmunofluorescence test to provide a routine serodiagnostic test for chlamydial infection. Journal of Clinical Pathology 30, 510-517.

Treharne, J. D., Dines, R. J., and Darougar, S. (1977b). Responses to chlamydial ocular and genital infections in the United Kingdom and Middle East. In Nongonococcal Urethritis and Related Infections, pp. 249-258. Edited by D. Hobson and K. K. Holmes. American Society for Microbiology: Washington, D.C.

Wiesner, P. J. (1977). Selected aspects of the epidemiology or nongonococcal urethritis. In Nongonococcal Urethritis and related Infections, pp. 9-14. Edited by D. Hobson and K. K. Holmes. American Society for Microbiology: Washington, D.C.

Woolfitt, J. M. G., and Watt, L. (1977). Chlamydial infection of the urogenital tract in promiscuous and non-promiscuous women. British Journal of Venereal Diseases, 53, 93-95. 